No letter should be more than 400 words.

For letters on scientific subjects we normally reserve our correspondence columns for those relating to issues discussed recently (within six weeks) in the BMF.

We do not routinely acknowledge letters. Please send a stamped addressed envelope if you would like an acknowledgment.

Because we receive many more letters than we can publish we may shorten those we do print, particularly when we receive several on the same subject.

\section{Problems of diabetics in prison}

SIR,-The paper by Drs G V Gill and I A MacFarlane presents a sad picture of poor care of a chronic disease in an establishment that has a higher incidence of a chronic illness than occurs in the general population.

I found it almost unbelievable that the Prison Directorate stated that there are deliberately no written regulations for managing diabetic subjects in jail to permit flexibility and to protect the doctor-patient relationship. There is no point in having flexibility and a good doctor-patient relationship if prisoners become ill and perhaps are in danger of death.

High class diabetic care can be delivered in general practice, even in practices in which the turnover of patients is high. In my practice most diabetic patients, those with insulin dependent as well as non-insulin dependent diabetes, are looked after solely by the practice miniclinic run by members of the primary health care team. I do not understand why this cannot work in prison when prisoners are kept under much more controlled conditions than patients in a general practice. Remand prisons may have considerable difficulties because of the high turnover of patients, but diabetic care should be easier to manage in long stay prisons than in general practice. I am not sure why prison medical officers need to have their patients attending a consultant diabetic clinic outside the prison with all the security problems that this entails. In Bedford Prison when a diabetic prisoner is accepted into the prison the same survey is carried out as in our practice diabetic clinic, a treatment protocol is drawn up, and the prisoner is reviewed monthly.

It is vital that a protocol for diabetic care in prison should be drawn up by prison medical officers in discussion with diabetic consultants, which should be regularly and reliably used for all diabetic prisoners. Moreover, regular audit of the standard of diabetic care should be carried out in all prison establishments with peer review of the quality of care and publication of the results. We have reported such results from this practice over several years from $1984 .^{2}$

If competent diabetic care is not currently possible in the prison medical service what is needed is not that it should be taken over by consultant diabetologists, rather that the prison medical officers should have further training so that they can care for diabetic prisoners.

E MARTIN

Bedford

1 Gill GV, MacFarlane IA. Problems of diabetics in prison. $\mathrm{Br} M e d$ f 1989;298:221-3. (28 January.)

2 Martin E, Goodwin S. Audit of diabetic care. $\mathcal{A} R$ Coll Gen Pract 1988;38:123-4.
SiR,-Drs C V Gill and I A MacFarlane present convincing data that there is room for improvement in diabetic services in prisons. ${ }^{1}$

In the final example of suboptimal delivery of care they imply that because a patient's haemoglobin $A_{1}$ concentration had fallen from $9 \cdot 8 \%$ to $8.9 \%$ a change of treatment, from beef to human insulin, and re-education by a dietitian and a diabetic nurse had improved his diabetic control.

A seemingly not well appreciated fact is that changes in laboratory results occur owing to inherent analytical imprecision $\left(\mathrm{CV}_{\mathrm{A}}\right)$ and intrinsic biological variability $\left(C_{B}\right)$. For a significant change to have occurred (at $p \leqslant 0.05$ ) the difference between sequential results must be more than $2.77\left(\mathrm{CV}_{\mathrm{A}}{ }^{2}+\mathrm{CV}_{\mathrm{B}}{ }^{2}\right)^{1 / 2 .}{ }^{2} \mathrm{~A}$ good laboratory is unlikely to achieve long term analytical imprecision less than $3 \% ; 5 \%$ has been said to be satisfactory for patient care. ${ }^{3}$ Biological variation in stable diabetic patients is $7 \%$ (unpublished observations). ${ }^{4}$ Thus even in ideal circumstances a change of more than $21 \%$ is required before two consecutive haemoglobin $\mathrm{A}_{1}$ results can be stated to be significantly different. In this case a fall from $\mathbf{9 \cdot 8 \%}$ to $\mathbf{7 \cdot 8 \%}$ or less would be required for significance.

We urge the users of laboratory services not to overinterpret numerical results.

YVONNE FOGARTY CALLUM G FRASER

Department of Biochemical Medicine, Ninewells Hospital and Medical School, Dundee DD1 9SY

1 Gill GV, MacFarlane IA. Problems of diabetics in prison BrMed f 1989;298:221-3. (28 January.)

2 Fraser CG. Interpretation of clinical chemistry laboratory data. Oxford: Blackwell Scientific Publications, 1986.

3 Goldstein DE, Little RR, Wiedmeyer HM, et al. Glycated hemoglobin: methodologies and clinical applications. Clin

4 Petersen PH, Larsen ML, Horder M. Prerequisites for the maintenance of a certain state of health by biochemical maintenance of a certain state of health by biochemical
monitoring. In: Harris EK, Yasaka $M$, eds. Maintaining monitoring. In: Harris EK, Yasaka M, eds. Maintaining a
healthy state within the individual. Amsterdam: Elsevier, 1987: healthy

\section{Sudden infant death syndrome: faulty maturation of haemoglobin and immunoglobulins}

SIR, - The original purpose of the Oxford survey of childhood cancers was to discover why the 1935-55 trend of mortality was so different for two types of juvenile leukaemia (lymphatic and myeloid).' As well as establishing a causal relation between childhood cancers and prenatal $x$ ray examinations this and related surveys have made it increasingly certain that all childhood cancers have fetal origins and that until antibiotics were discovered deaths from infection masked the true frequency of leukaemias. ${ }^{2.5}$ But these observations only added to the mystery of why, after the discovery of drugs which compensated for defective immune responses, juvenile myeloid leukaemia was alone in making no contribution to a worldwide increase in mortality from leukaemia.

The first hint of any connection between this problem and that of the sudden infant death syndrome came when it was discovered that, in a consecutive series of 159 deaths from leukaemia before 6 months of age, which included all the British cases from 1953 to 1970 , only 48 (or $30 \%$ ) had followed July to December births. ${ }^{6}$ The most likely cause of this seasonal bias was a competing cause of death which was commoner in the winter than the summer and (unlike infections) had not decreased in frequency in recent years. The one cause of death to meet these requirements was the sudden infant death syndrome and, sure enough, in a series of 385 cot deaths before 6 months of age, 243 (or 63\%) had followed July to December births.

By this time haemotologists had discovered that in juvenile myeloid leukaemia classical signs of myeloid leukaemia are accompanied by abnormally high levels of fetal haemoglobin and other signs of faulty erythropoiesis. ${ }^{7}$ There were no comparable findings for sudden infant death syndrome, but since then Giulian et al have described postmortem findings suggestive of difficulty in switching from fetal to adult haemoglobin $^{8}$ and $\mathrm{Dr}$ Kevin Forsyth and colleagues have shown altered immunological control in the respiratory tract (or unusual responses to trivial infections). ${ }^{9}$ Therefore in cases of juvenile myeloid leukaemia competing causes of death might include sudden infant death syndrome as well as infections.

This hypothesis assumes that juvenile myeloid leukaemia is initiated shortly after conception and may therefore have faulty development of erythrocytes and myelocytes as a typical side effect. The red cell defect causes difficulty in replacing fetal with adult haemoglobin and the white cell defect causes difficulty in replacing passive with active immunity. The second weakness (which carries a high risk of deaths from infection) is common to all leukaemias with embryonic origins, but the first weakness (which carries a high risk of death from tissue anoxia) is more typical of myeloid than of lymphatic leukaemias.

On this hypothesis there might be a connection not only between juvenile myeloid leukaemia and sudden infant death syndrome but also between sudden infant death syndrome and death from anoxia during the second stage of labour. An appropriate test would therefore include (a) measurements of fetal haemoglobin in a series 
of live births and stillbirths large enough to produce several examples of unexplained stillbirths and sudden infant death syndrome and (b) routine testing of different types of haemoglobin and immunoglobulins in infants with leukaemia or severe pulmonary infections.

Finally, if these tests succeeded in establishing a link between juvenile myeloid leukaemia and sudden infant death syndrome then steps could be taken to discover whether the cancer inhibitor effects of immunisations observed in the Oxford survey data ${ }^{10}$ have counterparts in sudden infant death syndrome. This would necessitate giving immunisations to infants with abnormally high levels of fetal haemoglobin and comparing (under the usual conditions of controlled clinical trials) the frequency of sudden infant death syndrome in infants with and without these boosts to their immune systems.

ALICE M STEWART

Department of Social Medicine,

Medical School,

University of Birmingham,

Birmingham B15 2TJ

1 Hewitt D. Some features of leukaemia mortality. British fournal of Preventive and Social Medicine 1955;9:81.

2 Stewart AM, Hewitt D. Leukaemia incidence in children in relation to radiation exposure in early life. In: Ebert $M$, Howard A. Current topics in radiation research. Vol 1. Amsterdam: North Holland, 1965:223-53.

3 Stewart AM, Kneale GW. The age distribution of cancer caused by obstetric $x$ rays and their relevance to cancer latent periods. Lancet 1970;i:4-8.

$4 \mathrm{Kneale} \mathrm{GW}$. The excess sensitivity of preleukaemics to pneumonia: a model situation for studying the interaction of pneumonia: a dise situation for studying the interaction of an infectious disease with cancer. B
and Social Medicine 1971;25:152-9.

5 Stewart AM. Epidemiology of acute (and chronic) leukemias. In: Roath S, ed. Clinics in haematology. London: W B In: Roath S, ed. Clinic

6 Stewart AM. Infant leukaemias and cot deaths. $\mathrm{Br}$ Med $\mathrm{J}$ 1975;ii:605-7.

7 Weatherall DJ, Edwards JA, Donahue WTA. Haemoglobin and red cell enzyme changes in juvenile myeloid leukaemia. BrMed f 1968;i:679-81.

8 Giulian GG, Gilbert EF, Moss RL. Elevated fetal haemoglobin levels in sudden infant death syndrome. $N$ Engl $\mathcal{F} \mathrm{Med}$ 1987;316:1122-6.

9 Forsyth KD, Weeks SC, Koh L, Skinner J, Bradley J. Lung immunoglobulins in the sudden infant death syndrome. BrMed f 1989;298:23-6. (7 January.)

10 Stewart AM, Kneale GW. The immune system and cancers of fetal origin. Cancer Immunology and Immunotherapy 1982;14: fetal or.

\section{Lung immunoglobulins in the sudden infant death syndrome}

SIR,-Dr Kevin D Forsyth and colleagues comment on the presence of cells positive for immunoglobulin in the terminal airways and alveolar interstitium of infants with sudden infant death syndrome.

The staining characteristics suggested that these cells were plasma cells; they were present in increased numbers compared with those in a control group and were the probable local source of the increased immunoglobulin concentrations measured in lung lavage fluid of the infants with the syndrome. The presence of these cells has, however, been known for some time, and the speculation on their possible role in infant death has scarcely changed since.

A cogent and clear headed account of personal experience of sudden deaths in infancy has been given by Barrett, ${ }^{2}$ which is recommended to those wishing to assess how much understanding of sudden infant death syndrome has advanced in the intervening 35 years since it was produced. It describes the occurrence of mononuclear cells (lymphocytes, histiocytes, and plasma cells) in or around the bronchi as being a characteristic feature of cases of sudden unexplained death in infancy. Like Dr Forsyth and colleagues he thought that acute inflammation or infection was an unlikely cause and that a hitherto unrecognised respiratory pathogen might be responsible but that the reaction suggested more of a "continued mild irritation" and was unlikely to provide a satisfactory explanation of a sudden death (similar cellular infiltrates were described in an infant who died of accidental acute asphyxia ${ }^{2}$ ).

The fact that much of the discussion concerns the possible roles of postnatal age, time of year, sleeping position, inhalation of stomach contents, and acute infection versus asphyxia should give us cause to reflect how much we have advanced in the interim.

T G MATTHEWS

Rotunda Hospital,

G P P FOX

Dublin

1 Forsyth KD, Weeks SC, Koh L, Skinner J, Bradley J. Lung immunoglobulins in the sudden infant death syndrome. Br.Med f 1989;298:23-6. (7 January.)

2 Barrett AM. In: Gairdner D, ed. Recent advances in paediatrics. London: Churchill, 1954:301-20.

\section{Botulinum toxin}

SIR, - While highlighting the use of botulinum toxin for various ophthalmological dystonias, the editorial by Dr Roger C Humphry also mentions its use in treating spasmodic torticollis and spastic dysphonia.' We report the use of botulinum toxin in treating yet another type of muscle dystonia.

Anismus or pelvic outlet obstruction seems to be due to a failure of the puborectalis muscle and the external anal sphincter to relax during attempted defecation and can be diagnosed on integrated pressure-electromyographic proctography. ${ }^{2}$ Previous attempts at treating this condition have been disappointing. In a pilot study we have obtained encouraging results by injecting botulinum type A toxin into the puborectalis muscle. ${ }^{3}$ To date the treatment has not elicited systemic side effects or antibody production in our patients; the risk of this, however, must be small as the dose of the toxin required to weaken the puborectalis muscle ( $3 \mathrm{ng}$ ) is similar to that used to treat patients with blepharospasm, in whom such complications have not yet been reported.

Dr Humphry's editorial also mentions the use of botulinum antitoxin to reverse unwanted paresis. The antitoxin is, however, effective only if it is injected soon after the toxin and cannot reverse or decrease established muscle weakness. ${ }^{+}$The scope for therapeutic application of the antitoxin is therefore limited.

We are currently evaluating the therapeutic and toxic effects of botulinum type A toxin in treating anismus in a prospective controlled trial.

RODNEY I HALLAN

Surgical Unit,

The London Hospital

London El 1BB

1 Humphry RC. Botulinum toxin: a new ally of an old adversary. BrMed f 1989;298:136-7. (21 January.)

2 Womack NR, Williams NS, Holmfield JHM, Morrison JFB Womack. NR, Williams NS, Holmfield JHM, Morrison JFB,
Simpkins KC. New method for the dynamic assessment of Simpkins KC. New method for the dynamic assessment

3 Hallan RI, Williams NS, Melling J, Waldron DJ, Womack NR, Morrison JFB. Treatment of anismus in intractable constipation with botulinum A toxin. Lancet 1988;ii:714-7.

4 Scott AB. Antitoxin reverses botulinum side effects. Eye 1988;2 29-32.

SIR, - The report from the United States quoted by Dr R C Humphrey, that patients suffering from spastic dysphonia derive benefit from an injection of minute doses of botulinum toxin, ${ }^{\prime}$ is supported by our experience. ${ }^{2}$ Although spastic dysphonia is an uncommon condition, we have examined and treated many cases referred to our specialist voice clinic. It is characterised by severe adduction of the vocal folds during phonation, which produces a broken pattern of speech described as "trying to talk while being choked." The consequen inability to communicate effectively results in many patients becoming social recluses.

Severely incapacitated patients who have failed to respond to intensive speech therapy or drugs, or both, are offered an injection of botulinum toxin into the left vocal fold. The procedure is performed under local anaesthesia by introducing an electromyographic needle with a lumen into the left thyroarytenoid muscle. ${ }^{3}$ Diluted botulinum toxin type $\mathrm{A}$ is injected once optimal siting has been achieved. Patients have noted an improvement in their fluency of speech within 48 hours.

The first three patients were admitted for observation after the injection but no untoward side effects were noted either from the needle or the toxin. Further procedures are being performed on an outpatient basis. All patients have agreed to a repeat procedure, if necessary, after the muscle recovers function in three to four months.

From our experience this form of treatment should be offered to patients with severe intractable spastic dysphonia.

D GARFIELD DAVIES R S DHILLON

Voice Clinic,

Ferens Institute of Otolaryngology,

Middlesex Hospital,

London WIP 5FD

1 Humphrey RC. Botulinum toxin: a new ally for an old adversary Br.Med F 1989;298:136-7. (21 January.)

2 Blitzer A, Brin MF, Fahn S, Lange D, Lovelace RE. Botulinum toxin for the treatment of "spastic dysphonia," as a part of trial of toxin injections for the treat of as a part of a trial of toxin injections for the treatin
disorders. Laryngoscope 1986;96:1300-1.

3 Miller RH, Rosenfield DB. The role of electromyography in clinical laryngology. Otolaryngol Head Neck Surg 1984;92. $287-91$

\section{Merit awards}

SIR,-Dr Donald M Wayte ${ }^{\prime}$ criticises Dr B A Evans for saying that the award system is corrupt ${ }^{2}$ and then proceeds to offer as proof of its integrity a description of the system as it operatesapparently satisfactorily - in Wales.

But would it not have been more relevant to ask Dr Evans for proof of his allegations? And how damning would any evidence have to be before $\mathrm{Dr}$ Wayte believed it; before he believed that human weakness and cupidity can occasionally exist in doctors who stand to gain-sometimes for close friends - pay rises of $£ 6000-£ 30000$ a year? Are doctors genetically so different from those cousins who, apparently working honourably "with fairness and honesty," have been insider dealing on the Stock Exchange or participating in takeover scandals in the city? Does natural selection (distinction even) preclude hospital consultants from being tempted into occasional avarice and nest feathering?

There are, of course, good reasons why Dr Evans might be reluctant to give $\mathrm{Dr}$ Wayte examples of behaviour which if not corrupt are extremely disturbing and in their ambiguity legally perilous to expose. It is not surprising that the system, conveniently cocooned in secrecy, inherently presents opportunities for manipulation by those few who do not share Dr Wayte's palpable honesty. Surely it is important for the system to be seen to be operated with honour, fairness, and honesty? To achieve this three fundamental reforms have been called for: firstly, a clear and well defined constitution; secondly, a method of supervising or checking on that constitution as operated at district level; and, thirdly, the abolition of all secrecy. ${ }^{3+}$

It has been emphasised that if the profession did not make the alterations others would do so. ${ }^{3}$ The government is now about to do this. ${ }^{5}$ Unhappily, the proposed changes seem unlikely to deal with the most important failings and may merely succeed in making the principles that comprised the only real justification for an award system 